\title{
Propedéutica a una definición del "maestro colombiano". Una mirada desde las Prácticas Pedagógicas
}

\author{
Alejandro David García V. \\ Martha Isabel Barrero $G$. \\ Amparo Cuenca W. \\ Grupo de Investigación IPPE
}

\section{El maestro colombiano}

$\mathrm{P}$ ara acercarse, comprender y luego escribir sobre la identidad del maestro (en adelante IM), es necesario examinar su historia desde las prácticas pedagógicas con el fin de identificar las teorias que han sustentado la organización curricular y administrativa de la institución educativa y asi proyectar en el mundo de hoy que tipo de docente se precisa para enfrentar los retos actuales como es un mundo globalizado con todas sus implicaciones económicas, tecnológicas, sociales, personales y culturales.

Rodriguez (2009,13), plantea cuatro hitos ${ }^{1}$ fundantes en la constitución de la imagen del maestro en Colombia. El primero hace referencia al ejercicio de la docencia como apostolado -los maestros como abnegados modeladores del alma nacional-y caracterizado por el énfasis en las condiciones morales antes que el manejo apropiado de conocimientos, la escasa formación docente, aspecto que viene desde la colonia hasta el siglo XIX; otro elemento influyente es el abandono estatal al que estaba sometido y que se refleja sobre todo en los atrasos y bajos salarios. "Tan grave era el problema de los salarios que la primera huelga registrada en el magisterio se debió a ocho meses de atraso en el pago a los maestros de Nariño en 1919." El segundo, es el determinado por la prioridad del método en la práctica docente; la autora afirma que desde 1821, con la aparición de las Escuelas Normales, el método de enseñanza juega un papel protagónico en la formación de maestros, donde ya el saber pedagógico estaba ausente. En 1935 bajo la influencia de la pedagogia activa, tanto en estas escuelas como en las primeras facultades de educación aparecen métodos de enseñanza basados en la inducción y la experimentación, es el sincretismo de los métodos activos (Decroly) con el objetivo (Pestalozzi), eso sí, sin dejar atrás los fines educativos de carácter moral y religioso. Las transformaciones de los currículos de las escuelas normales a mediados de la década del sesentá enfatizan en técnicas de aprendizaje fundadas en la tecnología educativa y la

${ }^{1}$ RODRIGUEZ, Rosa Helena. El maestro en Colombia. Bogotá, Universidad Distrital Francisco José de Caldas. 2009. 
psicologia conductista. Dicha transformación la realiza la tercera misión alemana en 1968 con la elaboración de guías para el desarrollo de los nuevos planes de estudio, de material didáctico y capacitación a los maestros en el empleo de este material.

En las facultades de educación se adelantó un proyecto pedagógico de indole popular que "abogó por una formación integral que vinculara la realidad del pais con una formación pedagógica, cultural y cientifica, el cual promovía la profesionalización docente. Al igual que otros, este proyecto político pedagógico liberal de la década del treinta tropezó con los obstáculos del dogmatismo religioso y en 1951 la Escuela Normal Superior fue clausurada por presiones de tipo político; pues los conservadores lo consideraron como el foco de fuerzas oscuras que patrocinaron el Bogotazo en 1948".2

En la década del sesenta las facultades de educación fueron las encargadas de difundir el diseño instruccional de enseñanza-aprendizaje. A su vez sufrieron una transformación con una nueva racionalidad organizativa ya que, introdujo la departamentalización. Esto significó que las facultades de educación se dedicaran a lo instrumental y didáctico y las demás facultades al saber cientifico y tecnológico.

"Esta división discursiva del saber marginó a los futuros maestros de la posibilidad de comprender los procesos de producción del conocimiento, de la explicación de cómo se construye una disciplina particular y, sobre todo, de la posibilidad de cuestionar su práctica, condenándolo a transmitir resultados producidos por otros. Lo cual ha hecho del maestro un administrador y ejecutor y de la pedagogia, un saber operativo, una técnica a la cual no se le reconoce su especificidad histórica y social".

Concluye la autora: por eso la práctica del docente enfatiza en lo disciplinar, es decir, en tener control de su clase y el manejo de la autoridad; aspecto que aleja al docente de su saber especifico que es el pedagógico, pues lo hace prisionero del método y dependiente del texto escolar e históricamente en un administrador del currículo. La importancia dada al método recalca la importancia de la experiencia en el ejercicio de la enseñanza, pues es en la práctica que se va ajustando el método. De ahi que la practica hace al maestro.

El tercer hito, el maestro como trabajador asalariado, concebido desde la lucha por un estatuto docente que regulara la carrera docente; la creación del escalafón nacional docente. Históricamente el primer escalafón docente se dio en Colombia en 1917, que se sustenta en la urgente necesidad de organizar al magisterio debido a las condiciones deplorables de los maestros y la falta de estímulos. En 1936 se creó un escalafón que fijó las bases sobre las cuales se deben calificar los maestros en servicio a partir de las siguientes condiciones: personales, administrativas, docentes, técnicas de enseñanza, examen, años de servicio, años de estudio, grado. Esto lleva a establecer en el Escalafón Nacional cuatro categorías de acuerdo al punto obtenido en las condiciones mencionadas.

En la década del setenta con la influencia de la organización sindical y la lucha de los maestros derrotaron dos decretos sobre el estatuto docentese logra el Estatuto Docente de manera conciliada Estado-magisterio, con el Decreto

${ }^{2}$ ibid. P. 38 
2277 de 1979, el cual regulara la carrera docente. A continuación se mencionan sus principales logros: la estabilidad laboral, ningún docente podrá ser destituido si se encuentra escalafonado; creo la carrera docente, que garantizó estabilidad y ascenso de los educadores en servicio; restringe el ingreso de otros profesionales para ejercer la docencia.

Este estatuto se caracteriza por ser gremialista, es decir casi todas las exigencias tienen que ver con condiciones salariales, además de contestatario, pues no logra impactar aspectos como la formación y la profesión docente, así como el saber del maestro, es decir, queda por fuera la dignificación de la profesión. En sintesis, la preocupación de los docentes se centró en la titulación: bachiller pedagógico, tecnólogo en educación o licenciado, con otras palabras, profesión significo titulación. "El análisis por la calidad de los programas y curriculos ofrecidos por Normales y facultades de educación no se dio. Tampoco en materia de capacitación se dio un tipo de exigencia sobre la calidad y pertinencia de las temáticas...sin entrar a cuestionar aspectos como la instrumentalización de la enseñanza, el uso casi obligatorio de las guias del 1710, sus principios filosóficos, etc. Esa falta de discusión por el saber pedagógico convirtió la capacitación en una feria del crédito". ${ }^{3}$

El Estatuto Docente ubica al maestro como funcionario estatal, como trabajador asalariado al servicio del Estado, de modo que las relaciones de dependencia con el Estado no cambian, todo lo contrario, se reafirman. En este sentido el Estatuto Docente es una herramienta legal, protectora de los derechos de los maestros como trabajadores estatales asalariados, pero no es un instrumento de profesionalización de la carrera docente.
Con el decreto 1278 de 2002 o mal llamado estatuto de profesionalización docente, el Estado de manera unilateral crea un nuevo estatuto que va en contravia de la dignificación de la profesión docente, pues este decreto abre la posibilidad a todos profesionales a ejercer la docencia, siempre y cuando apruebe el examen, pase el periodo de prueba y realice un curso de pedagogía.

En el último hito, el maestro como sujeto de saber y trabajador de la cultura, se enmarca en el movimiento pedagógico que se dio en Colombia en la década del ochenta, el cual busca posicionar al docente como profesional de la educación y trabajador de la cultura. Innovador porque pretendió trabajar la imagen del maestro y propositivo porque generó producción pedagógica a partir de las investigaciones sobre las prácticas. Si bien no logró impactar en las prácticas de los maestros colombianos en su totalidad, es significativo para un grupo de docentes que han logrado incidir en la educación del país.

Un primer quiebre del Movimiento es que rompe con los esquemas tradicionales de gremialista contestatario y censurador. Este es un Movimiento impulsado por Fecode con ideas y proyectos en el ámbito educativo, pedagógico y cultural.

Otra característica con la que rompe es con la imagen del docente como apóstol signada desde tiempo atrás. Busca crear una imagen del maestro y su gremio, no solo como trabajador asalariado al servicio del Estado, sino como un sujeto de saber, con un compromiso y responsabilidad en el desarrollo de la educación y la cultura.

También genera una reflexión sobre el papel del

${ }^{3}$ IBIDEM. Pg. 54. 
maestro y la escuela, creando proyectos pedagógicos alternativos, la autoformación y la actualización pedagógica; también se estudian temáticas relacionadas con la reforma curricular.

Nuevas concepciones discursivas que rompen con los postulados de lucha de los maestros de la década del setenta, que bajo la influencia de la izquierda, llevó inmerso un lema de la educación: "Solo si cambia el sistema cambiará la educación", y que concibe la imagen del maestro como asalariado y reproductor del sistema social. Ahora la consigna del Movimiento es "Educar y luchar por la liberación nacional" "el magisterio se planteo su nuevo papel en las luchas que enfrentaria hacia el futuro, ya no como victima del sistema, sumiso y oprimido, sino como protagonista de su historia y como "intelectual orgánico"' 4 .

Fue un movimiento que criticó la Reforma Curricular promulgada a finales de la década del 70 , basada en el diseño instruccional, en el cual un grupo de expertos era el que decidía: cómo enseñar, que enseñar y como evaluar; reforma de bajo costo económico que asume al maestro como un administrador y ejecutor del currículo instrumental para mejorar el proceso educativo. Fue un diseño a "prueba de maestros", que deja de lado la profesionalización y la capacitación docente, entre otras condiciones; de ahí la reflexión del maestro en torno a su identidad y formación que lo convierte en un sujeto de saber. Ante este avance emerge el Movimiento Pedagógico, en la convergencia de ONG, maestros universitarios y de colegios, así como de organizaciones privadas, generando varios frentes de trabajo como:

Grupos de investigadores educativos. Compuesto por docentes de las universidades del
Valle, Pedagógica Nacional y Nacional; los cuales trabajaron en un proyecto interdisciplinario de historia de la practica pedagógica en Colombia. Se trabajaron dos frentes: uno sobre la identidad intelectual del maestro y la otra sobre la existencia marginal de la pedagogía.

Los centros de educación e investigación. Auspiciados por ONG y apoyados financieramente por entidades extranjeras. "en ellos se hace posible el afán por encontrar alternativas pedagógicas alternativas desde una perspectiva latinoamericana, sustentada en el desarrollo de la pedagogía como saber". Figuran entre otras el CINEP, Foro Nacional por Colombia.

Escuelas sindicales. El problema de la pedagogia no puede escapa del compromiso sindical, desde esta perspectiva aparecen el Instituto María Cano, el ISMAC, y otros.

En el XII Congreso realizado en Bucaramanga en 1982, la federación de profesores concretaron las siguientes tendencias:

1) Pedagógico-populista. Tiene como principio la pedagogia es el instrumento de la política; 2) de la practica pedagógica. Donde el maestro es concebido como soporte del saber y la pedagogia se reconceptualiza como saber especifico y diferenciado; 3) político pedagógica. El maestro es trabajador de la cultura, la pedagogía no se reduce a la enseñanza, participa en la creación y transformación de los sujetos sociales en el ámbito de la escuela.

Para hablar sobre la identidad del maestro en Colombia hay que tener en cuenta también las reflexiones hechas por Oscar Saldarriaga ${ }^{5}$, quien plantea la necesidad de empoderar al docente 
como un sujeto de saber y no como un simple ejecutor de la práctica. Para el autor en la labor de maestro hay implícito una condición de subalternidad histórica que es de índole epistemológica y socio-cultural. Éste ha sido requerido históricamente para la transmisión de la cultura letrada del grupo hegemónico dominante, reproduciendo en las nuevas generaciones el ideal de vida de la clase imperante, tarea que cada día es más ardua y demanda mucho más tiempo.

Para Araceli de Tezanos, la imagen del maestro colombiano se ha dado una condición vocacional connotada a una imagen religiosa que vincula al maestro como "apóstol", y en tal sentido la docencia es un trabajo con una trascendencia social, es una misión personal que hay que cumplir socialmente. La autora asocia la vocación a sentimientos mesiánicos, que se concretan en servir a la sociedad; desde esta óptica la educación aparece como la "redentora" del pueblo y sobre todo de los pobres. El maestro es considerado según Kerschensteiner "como un individuo en el que domina un sentimiento fundamental de simpatia $e$ inclinación (amor) hacia sus semejantes. Una persona orientada socialmente... un hombre altruista" 6

Pero de acuerdo a De Tezanos, esta visión se ha transformado en la educación colombiana a partir de la década del 70, pues en el estudio hecho en las Escuelas Normales la vocación "se ha visto transformada en un proceso científico centrado en la detección de las capacidades para (actitudes) poder desarrollar cierto tipo de tareas. Esta detección se ha denominado "orientación vocacional 0 profesional"...que "se legitima en un proceso de selección adjetivado como cientifico".?

Para Rodrigo Parra ${ }^{8}$ la profesión docente parte de una paradoja: es un grupo homogéneo pero el medio social es diverso ${ }^{9}$; aspecto que genera una heterogeneidad en ellos. La imagen que tienen los maestros de la profesión se observa desde dos puntos de vista. El primero está centrado en las mpturas o incoherencias que esa imagen presentó en su relación con la realidad social y con la práctica docente ${ }^{10}$; el segundo en los conflictos que se generan en la formación docente: de un lado la orientación pedagógica y de otro lado la función social del maestro como formador de ciudadanos.

Hay que resaltar para la época la feminización del magisterio ${ }^{11}$ lo cual genera un impacto en la imagen del docente en cuanto a su profesión por cuanto socialmente se entiende la escuela como una prolongación del trabajo de la mujer como madre, lo cual entra en conflicto con el papel del maestro como un líder comunitario.

Prevalen dos imágenes en los docentes de carrera: a) el magisterio es una vocación que implica prestar un servicio a la sociedad; b) el maestro debe participar activamente en la vida de la comunidad con el propósito de guiarla hacia una mejor situación económica y cultural. "tal imagen de la función del maestro ha sido heredada de su actividad en una sociedad preindustrial $y$ de situaciones anteriores del pais, en las que predominaban el analfabetismo, y se conserva prácticamente incambiada a pesar de las

'DE TEZANOS, Araceli (1986). Maestros artesanos intelectuales. Universidad Pedagógica Nacional. CIID. Bogotá, pg 74.

${ }^{7}$ IBIDEM, Pg 65.

${ }^{8}$ PARRA, Rodrigo (1986). Los maestros colombianos. Capitulo II. La profesión de maestro y el desarrollo nacional. Plaza y janes. Bogotá.

${ }^{2}$ Nivel urbano, que se subdivide en marginal, no marginal y urbanización con y sin industrialización. A nivel rural, comprende economias campesinas, economias de agricultura industrial y economias de agricultura empresarial.

${ }^{10}$ IBIDEM. PG. 87.

"Las mujeres constituyeron entre el año 2000 y 2005 entre el $66,6 \%$ y $69,3 \%$ de la población total de docentes, con una especial concentración en los primeros niveles educativos, preescolar y básica primaria. (Bautista-2008) 
modificaciones que ha experimentado la sociedad colombiana con el advenimiento de la urbanización, industrialización, la expansión educativa y demás fenómenos concomitantes con una más compleja división social del trabajo"12 .

La nueva condición social, lleva a una ruptura con respecto al papel del maestro con su práctica, pues su imagen que el docente tiene de sí como líder de la comunidad se ve afectada, ahora se le pide a través de la imagen profesional que desempeñe actividades para las cuales no ha sido convenientemente entrenado, en efecto su formación carece de elementos para confrontar los cambios de la sociedad actual y por tanto su práctica se desajusta. Nuevas condiciones sociales tales como:

a. La naturaleza del proceso de desarrollo nacional lleva a diferenciar contextos sociales que implican cambios en su rol de líder comunitario.

b. El surgimiento de otras instituciones que cumplen funciones formativas no formales que entran a cumplir funciones de enseñanza y en este sentido compiten con los docentes que antes eran los únicos formadores.

c. El incremento de nuevas tecnologías educativas y a distancia que transforman el rol del docente, especialmente en la relación con el estudiante.

"La percepción de esta inconsistencia lleva al maestro a adoptar conductas que van desde el reforzamiento de su imagen tradicional de vocación pedagógica, del trabajo con "mistica" y el logra de grados relativos de eficiencia en su acción hasta la apatía y la anomía profesional, aduciendo las causas "externas" del bajo rendimiento escolar propio de los alumnos, o hasta un profundo desdoblamiento de su imagen profesional en que sostiene por una parte la importancia del trabajo con la comunidad y por otra, se desvincula de ella y se centra en la escuela y sus tareas especificas ${ }^{\prime \prime 3}$.

Pese a lo anterior, la imagen "sagrada" que en los docentes de la década de los 80 continua prevaleciendo es la del trabajo en la comunidad, a pesar de las condiciones sociales del momento que la hacen ineficaz, del proceso de feminización de la profesión, del incremento de nuevos docentes y su origen social, afectan la identidad del docente como líder social. Por el contrario los maestros valoran su oficio teniendo presente la imagen gratificadora que le ha dado la sociedad, y es esto lo que hace que siga apegado a la imagen "sagrada" de su profesión y defiende su vinculación con la comunidad sin importar el resquebrajamiento de su rol.

Otro elemento que analiza el autor son los efectos de las reformas educativas que traen consigo los avances en las ciencias y las humanidades, revaluación de conocimientos que no se genera en todos los contextos sociales, sino en ambientes de carácter urbano e industrial que son donde se desarrolla y utiliza mas efectivamente este tipo de saberes, lo cual hace que los maestros adapten sus prácticas más hacia estos entornos (urbanos de estrato medio y alto) que hacia los otros contextos (urbano marginal y rurales en todas sus variantes).

"Estas situaciones nuevas, ajenas en su mayoria al control del maestro, generan una redefinición básica del papel del maestro que no solamente afecta objetivamente su desempeño profesional, sino que le

\footnotetext{
12PARRA, Rodrigo. Opus cit. Pág. 117.

${ }^{13}$ Ibid. Pags. 118-9.
} 
crea una ruptura con la imagen de su tarea en la sociedad" 14 .

Existen dos elementos que prevalecen en la imagen actual del maestro; su carácter "sagrado" y su participación en la comunidad.

Transito de la imagen sagrada de la docencia a la imagen secular. Esta imagen surge de la idea vocación docente, en el sentido de una función altruista, como un servicio misional, "que da un significado a la vida y cuyo cumplimiento permea todos los actos de la persona y le confiere un estatus particular muy semejante a un sacerdocio". La imagen secular del educador tendería a ser una actividad profesional con obligaciones definidas y contenidas en la función docente, cuyos límites no traspasan el aula, y por lo tanto, no se extiende a actividades comunitarias no escolares. Desaparece la noción vocacional integral y el rol del educador se reduce a una ocupación que precisa de ciertas habilidades pedagógicas.

El maestro como líder comunitario. Esta imagen obedece a situaciones sociales que en el momento han sido superadas y se entiende mas a partir del tradicional maestro rural respetado y acatado, que compartía con el cura párroco y el alcalde la dirección de su comunidad. Esta función se ha desgastado y se ha vuelto conflictiva en algunos sitios, despojándolo de su carácter sagrado y líder comunitario. Además el aumento del alfabetismo y la escolaridad ha creado grupos educados y entrenados en actividades más prestigiosas y lucrativas impactando el rol del maestro como consejero general en asuntos culturales, y su imagen social. Esta secularización de la profesión puede conducir hacia la apatía o hacia actitudes críticas del sistema escolar.

\section{De la identidad a las formas identitarias de los docentes}

Dubar ${ }^{15}$ plantea que históricamente se han dado dos tipos de identidades, una esencial, fundada en la teoría del ser de Parmenides, caracterizada por la unidad e invariabilidad de la identidad, esto significa que el sujeto nace con una identidad y que esta es para siempre; la otra nominal, constituida en el devenir de Heráclito, descrita a partir de la diversidad y el movimiento, esto implica una identidad cambiante en la medida que el sujeto se relaciona con el mundo y con las demás personas. La identidad nominal será el punto de partida en este trabajo para analizar la construcción de las identidades docentes.

Como no hay una sola actitud de los profesores ante las creencias que tienen sobre su rol y su práctica educativa, tampoco existe una identidad unificada, sino formas identitarias múltiples, en proceso continuo de construcción y reconstrucción. En los profesores pueden habitar diversas identidades, dependiendo de los recorridos vitales y profesionales, de los contextos de trabajo o personales. La identidad es el resultado de un proceso dinámico entre las peticiones sociales o administrativas, de la enseñanza, y la afirmación de sí. En este sentido no es una entidad fija, sino que son el resultado de múltiples dinámicas identitarias.

Dubar $(1992,2000)$ citado por Antonio Bolivar et $a 1^{16}$, desarrolla la teoría de la identidad en la

${ }^{14} \mathrm{Ibid}$. Pg. 121.

${ }^{15}$ Dubar, Claude. La crisis de las identidades: la interpretación de una mutación. Editorial Bellaterra. Barcelona. 2002.

${ }^{16}$ Bolivar A, Gallego M. J, León M. J, Pérez P. Politicas Educativas de Reforma e Identidades Profesionales: El Caso de la Educación Secundaria en España. En Archivos Analiticos de Politicas Educativas. Volumen 13, numero 45, noviembre 23 de 2005. 
doble transacción (biográfica y relacional) según la cual, ésta se juega entre proyectos personales de identidad reivindicados "para si" sobre la base de la experiencia biográfica, y la identidad que le reconocen los "otros" (personas, sociedad o institución) por medio de categorizaciones o reconocimientos sociales. Todo el proceso, se establece como una transacción doble entre la identidad reivindicada (atribuida) y la identidad aceptada (o refutada) por el individuo concreto. Desde la identidad esencial, el sujeto construye su identidad desde el sí mismo, donde el otro aparece como una prolongación del yo; en cambio, en la identidad nominal, el si mismo aparece como una construcción que el sujeto hace desde la otredad, en este sentido, cómo me veo (identidad deseada) está determinado por la manera como me ven los demás (identidad atribuida).

En este sentido, la construcción de la identidad profesional docente, se articula en la "transacción" que hace el docente con el grupo social (estudiantes, padres de familia, directivos, y otros), como proceso de ajuste, siempre dinámico, en una doble transacción (interna y externa, subjetiva y objetiva).

La Transacción objetiva: Identidad para otros. Como transacción relacional el maestro pretende reconocimiento por los otros sujetos significativos. Se refiere, por tanto, a los procesos de atribución objetiva que tienen lugar en las instituciones o grupos, que operan entre las identidades atribuidas y aquellas que son asumidas/incorporadas. Es una transacción externa que intenta acomodar o equilibrar la identidad para sí y la identidad para otro (identidades atribuidas y/o asumidas);

La Transacción subjetiva: Identidad para si, es

${ }^{17}$ Dubar 11.

${ }^{18}$ Dubar 11 un proceso biográfico interno, que consiste en proyectar futuros posibles en continuidad o en ruptura con una trayectoria anterior. Los docentes asumen una identidad propia a partir de las trayectorias sociales, que opera entre las identidades heredadas y las identidades aspiradas. Es una transacción interna que busca sostener una parte de sus identificaciones anteriores (identidades heredadas) y el deseo de construir nuevas identidades en el futuro (identidades divisadas).

Desde la identidad nominal se construyen las categorías de análisis, en este sentido, cómo se vea el docente (identidad deseada) está determinado por la manera como lo ven los demás (identidad atribuida); siendo asi, la identidad es el resultado del conjunto de eventualidades que el sujeto vive en su cotidianidad. De esta manera la identidad nominal, se construye narrativamente, y "es el resultado de una doble operación lingüistica: diferenciación y generalización. La primera es la que tiende a definir la diferencia, la que incide en la singularidad de algo o de alguien en relación con los otros: la identidad es la diferencia. La segunda es la que busca definir el nexo común a una serie de elementos diferentes de otros: la identidad es la pertenencia común ${ }^{117}$. Desde esta perspectiva no hay identidad sin alteridad. Las identidades, tanto como las alteridades, varian históricamente y dependen del contexto de su definición, por eso las identidades de los docentes están asociadas con la materia que enseñan (sobre todo los profesores de secundaria), a sus relaciones con los estudiantes, a sus roles y las conexiones entre éstos y su vida fuera de la escuela. Conjunto de identidades de la persona denominadas formas identitarias, las cuales son "formas sociales de identificación de los individuos en relación con los otros y durante una vida"18. 
Formas identitarias que Ricoeur llama identidad narrativa constituida en la dialéctica idem/ipse o construcción del sí mismo como otro. Hay que entender que la mismidad o idem se determina por el carácter, mientras que el ipse por la palabra dada, de modo que son dos términos diferentes aunque tiende a confundirse el idem con el ipse, pues el carácter en su historia puede ocultar la actividad del yo como ipse.

"entiendo aquí por carácter el conjunto de signos distintivos que permiten identificar de nuevo a un individuo humano como siendo el mismo."113 "el carácter designa el conjunto de disposiciones duraderas en las que reconocemos a una persona" a partir de la sedimentación en las costumbres o identidades adquiridas que definen la mismidad. Pero en la constitución de la identidad, el carácter es el "qué" del "quién", es decir, a la pregunta que responde es ¿Qué soy? Y no ¿Quién soy?

Para responder la pregunta quién soy, Ricoeur afirma que: "Existe, en efecto, otro modelo de permanencia en el tiempo aparte del carácter. Es el de la palabra mantenida en fidelidad a la palabra dada...la palabra mantenida expresa un mantenerse a si que no se deja inscribir, como el carácter, en la dimensión del algo en general, sino, unicamente en la del quien" ${ }^{19}$.

Una cosa es que el sujeto sea por el carácter otra por la palabra dada. El cumplimiento de la promesa es un desafío al tiempo y al cambio: "aunque cambie mi deseo, aunque yo cambie de opinión, de inclinación, "me mantendré"'. Esto implica una permanencia en el tiempo que es opuesta a la del carácter.

El maestro a través de su identidad narrativa expresa con su carácter las generalizaciones que ha asimilado históricamente en su vida, es decir ha ayudado a cimentar una serie de comportamientos y conductas que lo hace pertenecer a un círculo común o grupo docente; a su vez, con la palabra dada ha logrado realizar las diferenciaciones que lo distinguen del resto de compañeros y asumir autónomamente el compromiso con el otro.

Para complementar, con el carácter el maestro se acoge a la normatividad vigente, es regulado por las normas, en este caso es un sujeto heterónomo; en cambio, con la palabra dada, el maestro construye su discurso desde su propia convicción, este es un sujeto autónomo. Es en esta relación entre idem e ipse, generalización y diferenciación es que se constituyen las identidades de los maestros.

\section{Categorías descriptivas}

NG: Narración de Generalización: es la singularidad del discurso que tiene el docente en relación con los demás actores educativos.

ND: Narración de Diferenciación: busca definir el nexo común que existe entre los diferentes discursos singulares de los maestros; es la pertenencia en común que tienen los maestros a partir de sus diferencias.

Categorias de análisis de las formas identitarias Se construyen teniendo en cuenta que en la dialéctica entre la transacción subjetiva y objetiva, se determina narrativamente en diferenciaciones y generalidades que agruparan cuatro posibles formas identitarias de los maestros. (Ver cuadro 1).

a. la generalización coincide con la diferenciación en la transacción subjetiva/objetiva $(G+D+)$.

${ }^{19}$ Ricoeur, Paul. Si mismo como otro. PG. 118 
Indica que los discursos educativos vigentes coinciden con las concepciones particulares de los docentes; esto significa un acomodamiento del docente a las condiciones educativas actuales.

b.la generalización no coincide con la diferenciación en la transacción subjetiva/ objetiva (G+D). Implica que el discurso hegemónico educativo es asumido acriticamente por los maestros, generalización que somete cualquier diferencia. Este desajuste fortalece el discurso oficial e invisibiliza el discurso de los maestros. c. la diferenciación no coincide con la generalización en la transacción subjetiva/ objetiva (G-D+). Es una ruptura entre el discurso del maestro con el instituido educativamente; los maestros resisten el discurso oficial ante la imposibilidad de ser reconocidos socialmente.

d.la generalización y la diferenciación no coinciden en la transacción subjetiva/objetiva (G-D-). Divorcio entre el discurso oficial y el discurso del maestro; divorcio entre lo que él desea y termina haciendo); Implica un completo desinterés por la docencia.

Cuadro 1. Categorías descriptivas y de análisis de las formas identitarias

\begin{tabular}{|lr|l|ll|}
\hline \multicolumn{4}{|c|}{ Formas identitarias de los docentes } \\
\hline $\begin{array}{l}\text { Núcleo Narrativo de } \\
\text { Generalización }\end{array}$ & Transacción subjetiva & \\
& G+D+, G-D+, G+D-, G-D- & $\begin{array}{l}\text { Núcleo Narrativo de } \\
\text { Diferenciación }\end{array}$ & \\
& & \\
& & \\
& Transacción objetiva & \\
\cline { 2 - 4 }
\end{tabular}

Una aproximación a las formas identitarias de los maestros en Neiva.

Con la hermenéutica, se analiza al docente como actor y como narrador; con el primero construye significados a través de sus interacciones con los otros; en este sentido el concepto de acción es clave para describir la identidad de los maestros en la medida que desentrañan sus diversos roles docentes dados en sus representaciones. Como narrador, el docente aparece como el autor de su propia historia, lo cual permite construir su identidad a partir del rol que ha jugado socialmente. En este caso, los docentes narran sus historias a través de entrevistas abiertas que se realizaron con 17 profesores de 7 instituciones de educación básica y media de Neiva. Vemos a continuación el análisis de una pregunta de dicha entrevista para desarrollar las categorías propuestas.

\section{Pregunta número 1: ¿Qué es para usted ser docente?}

Para analizar las preguntas el grupo investigador resalta que en este trabajo cuando se habla de identidad del docente, se describe el ser docente en el tiempo, es decir, desde los cambios que se 
han producido en su historia de vida y no desde un ser esencial, ahistorico, fruto de una abstracción ideal de ser docente.

En este sentido, teniendo presente a Parra, se parten de los siguientes supuestos:

a. El magisterio es una vocación que implica prestar un servicio a la sociedad. (misión de la vida);

b. El maestro debe participar activamente en la vida de la comunidad con el propósito de guiarla hacia una mejor situación económica y cultural (lider de la comunidad).

\section{Pregunta 1. Qué es ser docente}

Esta pregunta tiene como objetivo develar en las narraciones de los docentes las caracteristicas que constituyen su identidad profesional, con el fin de mostrar si en ellas prevalecen elementos de las formas identitarias del apostolado y servidor de la comunidad o si se han mutado o generado nuevas formas identitarias.

\section{Descripción y análisis de la pregunta}

El procedimiento a seguir en el análisis es el siguiente: a) descripción de las generalizaciones con sus diferencias; b) descripción de cada generalidad y diferencias, acompañada de su respectiva narración; c) interpretación del contraste; d) construcción de la forma identitaria. En las narraciones de los maestros se dan dos tipos de generalizaciones, una mayoritaria constituida a partir del núcleo narrativo formar (16), la otra, dada desde la condición de ser humano (1). El primer grupo narrativo general formar, está constituido por los siguientes discursos diferenciadores: 7 maestros asocian formar con conocimiento, 5 con ayudar a ser humanos, 2 con educar para la sociedad, 1 con transformar,
1 con mentalidad critica. Aparece otro núcleo narrativo general (nng) ser humano, con su núcleo narrativo diferencial (nnd) enseñar, concebido por un docente.

La generalidad formar vs las diferencias conocimientos. En este paso, se relaciona generalidad con diferencias para determinar si existe correspondencia entre ellas y poder construir la forma identitaria de los maestros. Con respecto al nng formar, en asocio con los nnd conocimiento (7) (a través de un conocimiento...pueda ayudar a formar; además de transmitir un conocimiento dar elementos de formación para la vida; llevar al máximo unos conocimientos, que lleven al estudiante, a una formación integral; es tratar de compartir un conocimiento; compartir un conocimiento y enseñar; compartir lo q usted conoce; es enseñar a aprender). Se puede afirmar que no hay correspondencia en su horizonte de sentido, pues en la generalización el discurso hace énfasis en el desarrollo de la personalidad del estudiante; mientras que las narraciones diferenciadoras asocian formar con la adquisición de saberes como guía para la formación del estudiante. Veamos la siguiente narración:

"Para mi ser docente es encargarme de un grupo de estudiantes para que a través de un conocimiento que yo pueda transmitirles o brindarles, dirigirles, como sea de acuerdo a como vaya a ser. Pueda ayudar a formar su forma de pensar, como entiende la vida, como va a ser ese proyecto de vida, como sería lo bueno, como seria lo malo, de pronto ayudarle a entender eso". E2

Esta ruptura entre generalidad y diferencias significa que en los docentes están más arraigadas las diferencias que la generalidad; ellos creen que la docencia está asociada a la formación, debido a influencia de las teorías modernas (desarrollo humano) y al bombardeo educativo del estado 


\section{PAIDEAaSurcolombiana 16}

con sus politicas profesionalizantes, pero lo que llevarían a cabo en sus prácticas sería la creencia de que ser docente es necesario el conocimiento después la formación. Las diferencias son muy fuertes y la generalidad queda relegada a ellas; esto implica que formar como generalidad impacte poco su hacer y continúe vigente la formación como instrucción, determinado por un imaginario todavía misional.

\section{Forma identitaria}

Misional-tradicional: concepto de formación ligado al ser docente como formar consolidado en la ruptura entre la generalidad y las diferencias; los docentes tienen el concepto de formación nominalmente, es decir, conocen las teorias que hacen alusión a la formación pero lo que tienen interiorizado es una mezcla de la imagen religiosa de lo misional con una pragmática construida a través del método de enseñanza. Es una transición incipiente de la docencia como enseñanza a la docencia como formación.

La generalidad formar vs diferencias ayudar a ser humanos.

Continuando con el siguiente núcleo diferenciador ayudar a ser humanos (4), (guia; servir a los demás; responsabilidad de ayudar a formar y contribuir a la formación de otros seres humanos; trascender en la vida del estudiante). Se puede decir que existe correspondencia entre el horizonte de sentido del nng formar y los nnd ayudar a ser humanos (4). Ser docente desde la generalidad y diferencias se consolida en una imagen antropológica.

"Ser docente es ser un sujeto interactuante con los otros sujetos que son los estudiantes y padres de familia, ser un formador, orientador, guia, un trabajador, persona que introvertida trata de formar integralmente a los jóvenes para la vida, para el futuro". E16 (guia)
Es una condición para ser docente el formar, pues ellos lo manifiestan en sus diferencias coherentemente como acompañar al otro en su proceso.

\section{Forma identitaria Burócrata-misional}

Surge de la complementariedad entre generalidad y diferencias. Esto significa que los docentes están interiorizando las nuevas concepciones asignadas a la docencia como es el de orientador de un proceso de formación, enseñanza y aprendizaje, acorde con las expectativas socio-culturales. Con otras palabras, han aceptado el discurso oficial en su práctica con todas las dificultades que ello pueda presentar ya que de manera tenue todavía se conserva la imagen docente de lo misional. Aqui existe una transición de un imaginario religioso a uno civil influenciado desde una visión antropológica.

La generalidad formar vs diferencias educar para la sociedad

Con respecto al siguiente nnd educar para la sociedad (2) (la formación de los futuros ciudadanos; educando personas para la sociedad y para el futuro) existe una coherencia en su horizonte de sentido entre la generalización formar y sus diferencias; ya que, es uno de los postulados oficiales la formación ciudadana, lo cual es asimilado por estos docentes.

"Yo pienso que esta carrera, el ser docente, es una de las carreras más importantes porque nosotros estamos, junto con las padres de familia y las personas que tienen a cargo esos niños...jóvenes que estamos formando y educando, personas para la sociedad y para el futuro". E1 
Forma identitaria Burócrata-misional

Similar a la anterior, con la particularidad de hacer énfasis en la construcción social. Para ellos, ser docentes es un acto formativo que tiene una connotación interactiva.

La generalización formar vs diferencias transformar/mentalidad critica.

Las últimas dos diferenciaciones generar una mentalidad critica (da la posibilidad de que el. estudiante-cuestione y reflexione) y transformar el ser (la transformación del ser en su manera de pensar, en su accionar) tienen relación en su horizonte de sentido con el nng formar; pues son docentes que tienen claro desde una mirada pedagógica su condición educativa, lo cual va en contravía de las políticas educativas técnicoinstrumentales y profesionalizantes que impone el estado. En este caso son docentes que manejan una responsabilidad social con un compromiso ético para una sociedad que precisa de gente activa y pensante. Leamos las narraciones:

"maestro en el sentido de que no es un instructor que va llevar unas formulas de manera mecánica al estudiante, sino que le da la posibilidad de que él cuestione y reflexione sobre eso que se le está dando y pueda irsele creando una mentalidad crítica, ser maestro significaria de que tuviera los pies sobre la realidad". E8

"...la transformación del ser en su manera de pensar en su accionar, a hacer y dejar hacer. Eso es educar ser docente". E1

\section{Forma identitaria critica-socio-personal.}

Esta complementariedad en el horizonte de sentido de la generalización y diferencias tiene su validez en la reflexión docente sobre su práctica y su preocupación por la formación del otro. Concepción que puede estar influida por las corrientes del movimiento pedagógico, o por la formación en estudios superiores.

\section{La generalidad condición humana vs enseñar}

La otra generalización sobre ¿qué es ser maestro? Viene dada de manera minoritaria a partir del núcleo narrativo condición humana, y su diferenciación enseñar. En esta narración la generalidad es la diferencia, pero lo cierto en este caso, es que el discurso oficial educativo de esta construcción no tiene aceptación, y se construye más bien desde una concepción filosófica y antropologica.

"...yo pienso que es lo máximo que puede hacer un ser humano porque siempre somos maestros, todos los seres humanos, como papas, en el barrio, en todo lado, ser maestro es la máxima expresión de la razón de ser de un ser humano porque es tener siempre a la disposición su conocimiento y los valores". E13

\section{Forma identitaria racional}

Tanto generalidad como diferencia se complementan, de modo que esta forma identitaria asume el ser docente desde una condición propia del género humano, como es la capacidad de aprender en todo momento. Es una forma identitaria elaborada a partir de la reflexión docente sobre la educación.

\section{Análisis de la generalización formar}

El horizonte de sentido consolidado en el nng formar, está anclado en el mundo social desde teorias modernas y políticas educativas estatales que se han impuesto en el mundo educativo y no a partir de las reflexiones de los maestros sobre su práctica. Resalta esta generalización la 
necesidad de reconocimiento social como lo más significativo que tiene el ser docente. Es una concepción objetiva determinada por una condición identitaria atribuida a condiciones externas y no a una reflexión docente sobre su quehacer.

Lo anterior significa que el concepto de formar que todavía perdura en ellos es desde lo misional, mientras que formar como un proceso de humanización, (Concepción ilustrada de formación humana) y desarrollo humano como lo pretende el estado, lo asume de manera nominal, es decir, reconoce los imaginarios oficiales explícitamente (hay que hacerlo porque así lo exige el estado) o con sus resistencias, (el estado pide que sea asi, yo lo hago a mi manera).

\section{Análisis de las diferencias}

Las diferenciaciones que no corresponden al horizonte de sentido de la generalidad se puede explicar a la concepción aun arraigada en muchos docentes, de que lo importante en el proceso educativo es el conocimiento, esto lo acerca más a una concepción objetiva del proceso educativo. Forma identitaria que se consolida con la imagen del docente como profesional de la educación, es un cambio de paradigma desde el mundo de lo social, donde formar empieza a consolidarse en su generalidad pero no en su diferenciación; comienza a emerger con fuerza esta forma identitaria, y disminuye la anterior que ligada la formación a la enseñanza. Es el paso de la formación como una finalidad humana a un medio para el desarrollo y cualificación de las fuerzas productivas capitalistas.

Diferenciaciones que se complementan con una imagen misional de la docencia y que Parra describe como: Transito de la imagen sagrada de la docencia a la imagen secular; imagen que surge de la idea vocación docente, en el sentido de una función altruista, como un servicio misional, "que da un significado a la vida y cuyo cumplimiento permea todos los actos de la persona y le confiere un estatus particular muy semejante a un sacerdocio". La imagen secular del educador tendería a ser una actividad profesional con obligaciones definidas y contenidas en la función docente, cuyos limites no traspasan el aula, y por lo tanto, no se extiende a actividades comunitarias no escolares. Desaparece la noción vocacional integral y el rol del educador se reduce a una ocupación que precisa de ciertas habilidades pedagógicas.

La correspondencia entre el nn formar en su horizonte de sentido con los nnd ayudar a ser humanos (4); educar para la sociedad (2); transformar (1), y mentalidad critica, visibiliza una concepción implícita de la educación en la que el proceso educativo sigue concebido desde una construcción subjetiva del apostolado pero con unos nuevos ingredientes de indole antropológico y social que determina en algunos docentes una preocupación y resignificación del otro; es el tránsito de la imagen sacra del maestro a una secular, pero con la peculiaridad que esta construcción tiene sus raíces en el apostolado docente.

En los casos mentalidad critica, transformar y enseñar (condición humana) podria explicarse a partir de un proceso reflexivo de la labor del maestro influenciada seguramente por el movimiento pedagógico, estudios superiores y que se valida en el tránsito de la imagen misional del maestro como servidor social a un docente de carácter crítico, que ya no es un lider comunitario, sino un sujeto pedagógico, donde el maestro es concebido como soporte del saber y la pedagogía se reconceptualiza como saber especifico y diferenciado. Es una incipiente 
formación crítica del profesorado como sujeto que reflexiona su práctica desde una manera más autónoma.

\section{Conclusiones}

Finalmente se puede ver en el análisis de esta pregunta que el nn formar se dan formas identirarias no homogéneas principalmente a partir de la diferencia, lo que implica que los maestros aun visibilizan en su sí mismo esa dicotomía entre lo tradicional y lo novedoso, aunque el yo social del maestro comienza a estar guiada por una visión innovadora de lo educativo. Lo anterior significa que el discurso dominante y oficial de la educación en la formación de profesionales de la educación, en la consolidación de una imagen secular de ser maestro aun no ha sido interiorizada por los docentes, pues aun prevalecen concepciones sacras de la docencia influenciada de elementos modernos, lo cual hace que emerja nuevas formas identitarias donde las diferenciaciones son muy fuertes y la generalidad muy débil; una, en la cual el docente tiene miedo de asumir los cambios sociales actuales; con la otra, el maestro tiene una visión critica y la sociedad no lo acepta.

Teniendo en cuenta los supuestos planteados, se puede afirmar que en los docentes impera una imagen desgastada del apostolado, pues esta ya no aparece en toda su dimensión como en la década del 80 , sino que más bien se da a partir de una concepción misional mezclada con nuevas formas identitarias propias de la época. También se puede establecer que desde las generalidades, esta imagen desaparece explícitamente; pues las políticas de Estado van más encaminadas en la formación de un profesional de la docencia, experto en manejar grupos numerosos de estudiantes, con un conocimiento de las tics y un reproductor de las competencias profesionales y laborales que el Estado desea implementar en el estudiante de hoy, pero implícitamente aun permanece en el imaginario y prácticas de muchos docentes en particular.

Con respecto al primer supuesto desaparece la forma identitaria tipica misional del discurso oficial docente, y la forma identitaria servidor de la comunidad no aparece ni en la generalización y minimamente en las diferencias, es una forma identitaria que desaparece del imaginario docente, pero a su vez emergen formas identitaria fruto de los misional, social e incluso oficial distanciada de los fines educativos estatales.

\section{Bibliografia.}

RODRIGUEZ, Rosa Helena. El maestro en Colombia. Universidad Distrital Francisco José de Caldas. Bogotá. 2009.

SALDARRIAGA Oscar. Del oficio de MAESTRO. Cooperativa editorial magisterio. Bogotá. 2003. Capitulo V. el maestro: ¿pedagogo, intelectual o...maestro?

DE TEZANOS, Araceli (1986). Maestros artesanos intelectuales. Universidad Pedagógica Nacional. CIID. Bogotá, pg 74 .

PARRA, Rodrigo (1986). Los maestros colombianos. Capítulo II. La profesión de maestro y el desarrollo nacional. Plaza y janes. Bogotá.

BOLIVAR A, GALLEGO M. J, LEÓN M. J, PÉREZ P. Políticas Educativas de Reforma e Identidades Profesionales: El Caso de la Educación Secundaria en España. En Archivos Analíticos de Políticas Educativas. Volumen 13, numero 45, noviembre 23 de 2005.

DUBAR, Claude. La crisis de las identidades: la interpretación de una mutación. Editorial Bellaterra. Barcelona. 2002. 
Formas identitarias de los docentes

\begin{tabular}{|c|c|c|c|c|}
\hline Narración & \multicolumn{4}{|c|}{ Formas identitarias } \\
\hline $\mathrm{NNG}$ & F. I. NG+ ND+ & $\mathrm{NG}+\mathrm{ND}-$ & NG- ND+ & $\mathrm{NG}-\mathrm{ND}-$ \\
\hline 1. formar & $\begin{array}{l}\text { critica- } \\
\text { socio- } \\
\text { personal. } \\
\text { (mentalidad } \\
\text { critica, } \\
\text { transformar) } \\
\text { Burócrata- } \\
\text { misional: } \\
\text { (ayudar a ser } \\
\text { humanos; } \\
\text { educar para } \\
\text { la sociedad) }\end{array}$ & & $\begin{array}{l}\text { Misional- } \\
\text { tradicional } \\
\text { (conocimie } \\
\text { nto) }\end{array}$ & \\
\hline $\begin{array}{l}\text { 2. Condición } \\
\text { humano }\end{array}$ & $\begin{array}{c}\text { Racional } \\
\text { (enseñar) }\end{array}$ & & & \\
\hline
\end{tabular}

